\title{
Artistas de rua: trabalhadores ou pedintes?
}

Street performers: workers or beggars?

Bruno Buscariolli Adele de Toledo Carneiro

Eliane Santos

\section{Resumo}

0 presente trabalho apresenta as principais características da interação entre artistas de rua e o público em diferentes horários, localizações e tipos de arte, utilizando-se do método da observação. Com os resultados, foi possível verificar relações entre os códigos observados, como o perfil social dos espectadores e o tipo de arte que apreciam e a contribuição financeira. Outros aspectos que influenciam na interação com 0 artista são a faixa etária do público e a localização geográfica da atuação. A pesquisa evidenciou que a performance dos artistas de rua é um fenômeno democrático, porém de modo geral esses profissionais são ainda vistos pela população como pedintes, e não como pessoas de carreira artística em construção.

Palavras-chave: artistas de rua; performance artística urbana; etnografia urbana.

\begin{abstract}
This paper presents the main features of the interaction between street performers and the audience at different times, locations, and types of art, using the observation method. The results enabled us to note relationships among the observed codes, such as the spectators' social profile and the kind of art they appreciate and to which they contribute financially. Other aspects that influence the interaction with the artist are the age group of the audience and the geographical location of the performance. The research showed that these artists' performance is a democratic phenomenon but, generally speaking, these professionals are still seen by the population as beggars, not as people whose artistic career is under construction.
\end{abstract}

Keywords: street performers; urban artistic performance; urban ethnography. 


\section{Introdução}

A arte de rua abrange inúmeros tipos de diversão, como música, circo, teatro, dança, estátua viva e grafite. Cerca de 450 artistas de rua de São Paulo estão cadastrados, divulgam perfil e programação de apresentações apenas no site www.artistasnarua.com.br (Artistas na Rua, 2015). A atuação desses indivíduos ganhou maior notoriedade a partir da sanção da lei municipal 15.776, ${ }^{1}$ que dispõe sobre apresentações de artistas de rua nos logradouros públicos do município de São Paulo.

Os números e novas leis parecem legitimar o artista de rua como profissional, importante para a promoção artística e cultural do País. No entanto, "o artista de rua já está numa condição marginalizada no Brasil" Esta é a opinião de Isadora Faro, artista circense que se apresenta nas ruas de São Paulo há quase dez anos. ${ }^{2}$

A realidade é dura. Artistas de rua procuram demonstrar seu valor como trabalhadores, mas boa parte da população ainda os enxerga como pedintes. Duas faces da mesma moeda? Difícil dizer. Trata-se de um fenômeno dinâmico e complexo, que poderia encontrar respostas em aspectos históricos, culturais, políticos e econômicos do Brasil. Talvez, além do contexto amplo, um bom ponto de partida para investigar essa questão seja em um olhar minucioso, orientado para as particularidades e para o cotidiano dos artistas de rua. Quem são eles? Como se apresentam? Em que lugares? Para quem? Como se relacionam com o público? Como o público se relaciona e avalia as atuações deles?
Essa pesquisa se baseia nessas perguntas e tem como objetivo analisar quais são as principais características que envolvem a interação entre artistas de rua e o público. Para isso, foram realizadas mais de 100 horas de observação de performances ao vivo de artistas de rua, principalmente na cidade de São Paulo. Cerca de 40 notas de campo foram elaboradas pelos pesquisadores e serviram de base para codificação e posterior análise dos dados. As principais categorias da pesquisa foram: artista, arte, ambiente, público e interação.

Os resultados são instigantes. Eles indicam que a reduzida visão para negócios e comportamentos ostensivos para arrecadar dinheiro são alguns dos fatores que levam parte da população a enxergar artistas de rua como pedintes. Parece haver um choque de classes econômicas e sociais nos ambientes de apresentação dos artistas de rua, dominados por profissionais com status já adquirido e incentivado pelo público de baixa renda. Existe também um caráter democrático do trabalho dos artistas de rua, em decorrência da diversidade de pessoas e de situações que permeiam o cotidiano deles.

Serão apresentados a seguir o referencial teórico, a metodologia, a análise dos dados, as conclusões e as considerações finais da pesquisa.

\section{Referencial teórico}

Este trabalho se baseou nas técnicas da etnografia para levantar dados e realizar as análises. Sabe-se que a etnografia tem fundamentos 
na antropologia e que, ao longo do tempo, foi incorporada aos estudos no campo da sociologia e dos estudos organizacionais.

A palavra "etnografia" tem origem grega e apresenta na sua etimologia o radical etno, que significa "cultura de um povo", e o sufixo grafia, que significa "escrita, descrição". No Dicionário Aurélio da Língua portuguesa (2005) a definição é apresentada como "um estudo descritivo de um ou vários aspectos culturais e sociais relacionados a um povo ou grupo social". Nesse aspecto, a abordagem metodológico-teórica se propõe a compreender a cultura de um determinado grupo social mediante a observação e o registro do observador-pesquisador.

A etnográfica surge no século XIX, em um momento marcado por mudanças epistemológicas do conhecimento, especificamente relacionadas à reação de historiadores e sociólogos quanto à filosofia positivista dominante. Os interpretativistas compreendiam que o objetivo das ciências humanas era a compreensão da ação humana e defendiam a relevância do conteúdo intencional e significativo dessas ações sociais (Schwandt, 2006). Nesse processo, o papel do pesquisador passa a ser de analisar e de compreender a ação social dos indivíduos através de uma rede de representações sociais complexas e subjetivas da realidade da qual ele mesmo faz parte. Logo, a partir dessa abordagem, a experiência vivida pelo pesquisador é uma extensão desse processo de análise, pois não é possível um completo distanciamento entre o pesquisador e o objeto pesquisado. A etnografia vai ao encontro dessa abordagem, pois propõe uma compreensão mais profunda sobre a vida social dos indivíduos.
0 fundador do método etnográfico foi Malinowski, que desenvolveu o método para seu trabalho de campo nas Ilhas Trobriand, com duração de dois anos, ainda na primeira metade do século XX. Malinowski (1976) destaca, a partir de seus estudos, a importância da observação participante como forma de conhecer intensamente a cultura de um determinado grupo social através do entendimento da sua totalidade (biologia, psicologia e relações sociais).

Dessa forma, o método etnográfico se apresenta como inovador no campo da antropologia por instigar os pesquisadores a interagir com o objeto pesquisado mediante observação participante, rompendo com paradigmas racionalistas. Na sua obra, fica clara a importância da abordagem interpretativista pautada no diálogo entre a observação participante e o texto etnográfico.

A obra de Malinowski, intitulada Os argonautas do Pacífico Ocidental, publicada em 1922, apresenta as reflexões e as críticas metodológicas do autor, especificamente no processo coleta e análise dos dados da pesquisa. Trata-se de importante leitura aos interessados pelo método, pois apresenta abordagem crítica do autor, além de apresentar os princípios básicos para a realização de pesquisa etnográfica: a) conhecimento da literatura etnográfica relacionada ao objeto de estudo; b) prática da observação participante a partir da vivência com os nativos; c) utilização de outros métodos, tais como genealogia, diários de campo entre outros.

Malinowski (1976, p. 25) considera como etapa fundamental da pesquisa etnográfica a formação de um esquema claro e firme de constituição social, bem como o destaque de leis, normas e fenômenos culturais relevantes. 
Esse esquema é importante para organizar as informações coletadas e contribuir para a construção "de um todo coerente".

Para Czarniawska (2007), o método etnográfico possibilita compreensões mais amplas quanto às atividades realizadas pelos indivíduos no ambiente em que atuam e interagem. Requer, no entanto, o estabelecimento de relações entre o pesquisador e o pesquisado, palco em que as diferenças e as similaridades de cada um vêm à tona.

Nesse aspecto, o método contribui na construção de análises e, também, na compreensão do fenômeno observado, principalmente com base em questionamentos pertinentes ao meio investigado e da lente teórica do pesquisador. Assim, as diferenças e as similaridades encontradas em campo tornam a etnografia uma experiência única ao pesquisador, não podendo ser transferida para um assistente/auxiliar de pesquisa, pois as inferências mais significativas emergem a partir dessa aproximação entre o pesquisador e o objeto pesquisado.

A importância da convivência entre o pesquisador e o nativo é justificada por Malinowski como oportunidade de aproximação da cultura do outro. Dessa forma, o pesquisador deixa de ser visto como um estranho e como elemento perturbador diante do grupo pesquisado, tornando possível captar percepções, memórias, crenças, experiências e costumes.

Um dos meios mais utilizados para a realização das etnografias é a observação participante, porém outras abordagens, como a observação não participante, também são utilizadas. Sobre a teoria dos estudos etnográficos, Sanday (1979) aponta que a observação participante em estudos etnográficos conta com 0 apoio de grande diversidade de técnicas para levantamento de dados. Entre as mais utilizadas, estão entrevistas estruturadas, entrevistas com informantes-chave e questionários. Uma definição bastante adequada a esse trabalho é a de Hammersley e Atkinson (1995) sobre o termo etnografia como método específico, ou grupo de métodos, que requer a presença de um pesquisador participante no cotidiano dos observados por um longo período, registrando tudo o que acontece no local e o que é dito pelas pessoas próximas.

Para Godoi, Bandeira-de-Mello e Silva (2006), a pesquisa etnográfica é composta por três momentos fundamentais. 0 primeiro momento refere-se à "concepção do campo temático de estudo", em que o pesquisador deve conhecer os estudos teóricos já realizados sobre 0 objeto que será estudado. 0 segundo momento é o da "realização do trabalho em campo". Nesse momento, os autores apontam a importância da observação atenta, tanto aos eventos facilmente identificáveis, quanto àqueles que requerem maior atenção do pesquisador para identificação. Por fim, a fase de "elaboração do texto etnográfico", que tem como objetivo narrar de forma minuciosa as percepções do pesquisador quanto ao objeto pesquisado, bem como suas reflexões e análises dos resultados à luz de um referencial teórico.

Esse método de pesquisa também apresenta dificuldades, muitas vezes intransponíveis. Como discute Van Maanen (1979), as observações em campo podem apresentar informações empíricas bastante variadas, cujas causas são difíceis de identificar e podem gerar barreiras para os pesquisadores, no que se refere tanto às informações levantadas empiricamente quanto à utilização do método teórico 
mais adequado para analisar essas observações. Além dos aspectos conceituais, existem aspectos práticos que podem dificultar a realização de uma etnografia, como o acesso ao fenômeno que se busca estudar, o acesso ao local, o contato ou a falta de confiança dos informantes e o tempo necessário para a ocorrência do fenômeno a ser estudado.

A elaboração de um estudo etnográfico exige que o pesquisador considere a oralidade das pessoas observadas ou entrevistadas, por meio da descrição das falas dos indivíduos entrevistados, sem intervir ou realizar julgamentos no que se está observando. Esse procedimento de registro do discurso oral dos indivíduos estudados deve sofrer o mínimo possível de influência do pesquisador, pois os detalhes e as peculiaridades das diferentes formas de comunicação também apresentam características que podem ser relevantes para a análise posterior. Segundo Flores-Pereira e Cavedon (2009), em uma pesquisa etnográfica, o pesquisador deve considerar o significado das narrativas dos indivíduos observados, uma vez que, durante a realização desse tipo de pesquisa, existe um relativo conflito entre a cultura própria e a cultura investigada, e as diferentes perspectivas não devem se misturar. A observação deve ser livre de julgamentos ou de conclusões antecipadas sobre o fenômeno observado.

Como afirma Van Maanen (2006), as evidências que resultam da pesquisa etnográfica, assim como o estilo e a interpretação delas, apresentaram mudanças ao longo do tempo, mas as descobertas e a abordagem de qualquer trabalho ainda continuam relacionadas diretamente com os argumentos presentes em algum texto e referenciados a aspectos narrativos específicos e não gerais. Uma discussão importante sobre esse tipo de trabalho é como garantir que os aspectos textuais entre diferentes pesquisas etnográficas seja o mesmo. Essa questão é fundamental para a textualidade e veracidade dos fatos e dos textos etnográficos.

\section{Metodologia}

0 método de pesquisa utilizado neste trabaIho é a etnografia. Trata-se de uma abordagem bastante adequada à investigação sobre os artistas de rua e à interação deles com o público, apesar de não ser a única possível. A coleta de informações ocorreu entre os meses de março e maio de 2015. Nela, quatro pesquisadores utilizaram técnicas de observação e elaboraram notas de campo e o posterior arquivo das principais informações coletadas. Para a análise dos dados, foram utilizados o processo de codificação e a categorização, tendo como base as técnicas da teoria fundamentada.

É possível encontrar artistas de rua em praticamente todos os dias da semana em cidades grandes, não somente em performance, mas também divulgando o próprio trabalho. No caso de São Paulo, a lei municipal n. 15.776 de 2013 regulou a apresentação desses artistas, permitindo, inclusive, a venda de produtos de sua autoria nas ruas. Além disso, desde 2012 está disponível o site "Artistas na Rua" 3 que, com o auxílio da empresa de turismo de São Paulo (SpTuris), divulga o horário, os locais de apresentação e outras informações sobre cada artista cadastrado.

Foi, a partir desse site, que o grupo de pesquisa selecionou a maior parte dos artistas observados. Em um primeiro momento, as observações se concentraram na avenida Paulista, 
no bairro Cerqueira César em São Paulo, em função da facilidade de acesso. Entretanto, ao perceber pouca variedade nos relatos, os pesquisadores decidiram realizar as observações em outros locais, abrangendo não apenas a região central de São Paulo, mas também regiões populosas das cidades de Belo Horizonte e Embu das Artes. Com esse aumento de abrangência, o grupo conseguiu maior diversidade de informações sobre os artistas e sobre a interação deles com o público.

Foram realizadas 102 horas de observação de performances de artistas de rua ao vivo. Nas três cidades, procurou-se realizar as observações de pesquisa em locais movimentados e, na maioria das vezes, já previamente mapeados por meio da internet. Houve, entretanto, observações realizadas sem planejamento, iniciadas quando algum dos pesquisadores encontrou, por casualidade, um artista de rua exercendo a arte.

As observações não seguiram roteiro preestabelecido, o que possibilitou uma análise primária geral e abrangente de diversos aspectos. A forma de elaboração das notas de campo ficou a critério de cada pesquisador, sendo utilizadas anotações diretas à mão ou narração com gravadores. 0 conteúdo dos relatórios também não seguiu um ritual específico, contendo, assim, tudo o que os observadores tiveram alcance no momento da observação e, por isso, foram redigidos em caráter confessional. Ao todo, foram escritos 39 diários, cada um associado a um exercício de observação junto a artistas de rua, atuando sozinhos ou acompanhados. Cada relatório correspondeu em média a 3 horas de observação em campo.

No total, foram observadas 48 apresentações, sendo alguns artistas observados mais de uma vez, por diferentes pesquisadores. Essa prática é considerada válida pela pesquisa, porque, ainda que seja o mesmo profissional, a performance poderia ser diferente, em função de fatores internos e externos.

Foram observadas, ao todo, 44 artistas, totalizando 37 artistas solo e 7 artistas em conjunto, tanto em dupla como em grupos numerosos. A maioria das performances observadas era de musical (ao todo, 28 observações), mas também foram realizadas observações sobre pinturas (3 observações), dança (4 observações), artes cênicas, como estátuas vivas (5 observações), e outras designações, como malabarismos, mágicos e entretenimentos ao vivo (8 observações). Sobre estes últimos, houve dúvida quanto à consideração deles como artistas, isto é, como profissionais de arte. Entretanto, foram incluídos no conjunto de dados para a pesquisa não só por estarem na rua, mas por apresentarem também características peculiares de artistas desses locais: improvisos e um nível mínimo de preparo ao oferecerem entretenimento ao público transeunte.

As observações, de forma mais direta ou indireta, contribuíram para uma mudança da atitude de grande parte dos artistas: em vários casos, os artistas modificavam a maneira de atuar quando notavam a presença constante do observador, possivelmente para impressionar ou arrecadar mais dinheiro. Dessa maneira, ainda que seja um limite de pesquisa, essa influência foi considerada metodologicamente aceitável durante a descrição dos acontecimentos e na redação dos diários de campo.

Após a condução de aproximadamente vinte observações, foi feito o exercício de codificação dos relatórios produzidos. A codificação representou uma releitura dessas 
observações, buscando encontrar, a partir de fatos relevantes e em comum, palavras-chave que definissem os fenômenos observados. Trata-se de um amplo processo de reanálise: primeiramente selecionando temas primários em comum para, em seguida, elencar grandes temas, que seriam associados aos trechos dos relatórios de pesquisa.

Ao observar as anotações obtidas após as primeiras observações, foram percebidos alguns elementos frequentes e comuns a todos os relatórios. A partir dessas recorrências, o grupo formou códigos de análise para a generalização dos dados, fundamentais para a análise do fenômeno como um todo. Durante a codificação, notou-se a preocupação inicialmente em percepções sobre 0 artista e na descrição da arte. Foram relatadas características físicas, como idade, gênero e vestuário. Foram também descritos a maneira como 0 artista conduzia a arte, o tipo de arte executada, a infraestrutura (ou a falta dela) para a apresentação, o nível de profissionalização ou experiência com a condução da performance, entre outros.

Houve ainda uma preocupação em relatar o ambiente da apresentação observada, ou seja, quais os locais escolhidos, se eram movimentados e propícios para a arte em execução e, até mesmo, detalhes, como horário, clima e fluxos de pessoas. Outro elemento muito recorrente nos relatórios diz respeito as pessoas que passavam próximo ao artista durante a apresentação, além da descrição desse público: idade, gênero, vestuário, se estavam em horário de trabalho ou não. A partir dessas considerações, foram percebidas notas de campo sobre a interação dos artistas com o público caracterizado no ambiente.

Dessa forma, os relatórios especificavam o público presente no ambiente, ou seja, descrevia as pessoas que estavam passando pelo local no momento da apresentação e aquelas que, além disso, interagiam de alguma forma com o artista. A forma de interação poderia ser negativa, demonstrando reprovação, indiferente (maioria absoluta dos casos) ou amistosa e simpática. Esta última foi a mais detalhada, pois frequentemente implicava a contribuição financeira do espectador. Nem toda relação positiva era acompanhada de contribuição em dinheiro para o artista como "pagamento" pela apreciação da sua arte.

Assim, de maneira geral, a partir dos relatórios de campo foram extraídos os códigos principais que direcionaram a análise da pesquisa: "Artista", "Arte", "Ambiente", "Público" e "Interação". Junto às dimensões de cada código, foi possível estabelecer as relações entre as variáveis da pesquisa.

0 grupo teve como base as categorias expostas no Quadro 1, que orientaram as codificações mais frequentes nas observações dos artistas em campo. Conforme exposto no quadro, os relatórios foram divididos em grandes categorias e subcategorias para especificar as dimensões e os níveis de variação.

A partir da formação dos códigos, foi estabelecido, sempre com base na frequência dos acontecimentos, relações entre essas variáveis, para elaboração de uma teoria sobre as apresentações dos artistas de rua e suas respectivas interações com o público. 
Quadro 1 - Principais categorias de análise

\begin{tabular}{|c|c|c|c|}
\hline Categoria & Subcategoria & Dimensão & Variações da dimensão \\
\hline \multirow{3}{*}{ Artista } & Características pessoais & $\begin{array}{l}\text { Exemplos: Gênero, Faixa Etária, } \\
\text { Classe Econômica / Social } \\
\text { Aparente, etc. }\end{array}$ & $\begin{array}{l}\text { Exemplos: Masculino / Feminino; } \\
\text { Acima de } 65 \text { anos; Alta / Baixa; etc. }\end{array}$ \\
\hline & \multirow{2}{*}{ Como ele está na hora } & Companhia & Sozinho / Acompanhado \\
\hline & & Vestuário & Casual / Artístico \\
\hline \multirow{3}{*}{ Público } & Características pessoais & $\begin{array}{l}\text { Exemplos: Gênero, Faixa Etária, } \\
\text { Classe Econômica / Social } \\
\text { Aparente, etc }\end{array}$ & $\begin{array}{l}\text { Exemplos: Masculino / Feminino; } \\
\text { Acima de } 65 \text { anos; Alta / Baixa; etc. }\end{array}$ \\
\hline & \multirow{2}{*}{ Como ele está na hora } & Companhia & Sozinho / Acompanhado \\
\hline & & Vestuário & Formal / Informal \\
\hline \multirow{4}{*}{ Ambiente } & \multirow{4}{*}{ Local de atuação } & Nível macro & Próprio para Arte / Movimentado \\
\hline & & Nível micro & $\begin{array}{l}0 \text { artista prepara / } 0 \text { artista não } \\
\text { prepara }\end{array}$ \\
\hline & & Infraestrutura & Mais elaborado / Menos elaborado \\
\hline & & Horário & Manhã / Tarde / Noite \\
\hline \multirow{4}{*}{ Arte } & Tipos de arte & $\begin{array}{l}\text { Exemplos: Musical, Cênica, Pintura, } \\
\text { etc. }\end{array}$ & Exemplos: MPB / Jazz / Rock, etc. \\
\hline & - & Profissionalização & Boa / Ruim \\
\hline & - & Performance & Boa / Ruim \\
\hline & & Orientação do artista & Público / Arte \\
\hline \multirow{3}{*}{ Interação } & - & $\begin{array}{l}\text { Maneira como o artista arrecada } \\
\text { dinheiro }\end{array}$ & Ativa / Passiva \\
\hline & - & Reações do público & $\begin{array}{l}\text { Amistosa - com dinheiro / } \\
\text { Amistosa - sem dinheiro / } \\
\text { Indiferente / Reprovação }\end{array}$ \\
\hline & - & Audiência & Numerosa / Vazia \\
\hline
\end{tabular}

Fonte: Elaborado pelos autores. 


\section{Análise dos dados}

Os dados recolhidos foram analisados a partir de cada categoria principal: Artista, Arte, Ambiente, Público, Interação. Posteriormente, foi possível verificar quais as relações entre as variáveis e, assim, inferir conclusões gerais sobre o fenômeno.

\section{Artista}

A questão que prevaleceu nas observações dos pesquisadores sobre os artistas de rua é o fato de a maioria absoluta deles ser do sexo masculino. Ao todo, somente foram relatadas apresentações de quatro mulheres, sendo duas acompanhadas de homens, como no exemplo de um casal de músicos bolivianos e de uma dupla musical. Essa constatação suscita grande curiosidade, pois trata-se de um fenômeno popular, que inclui diversos tipos de arte e locais de atuação, mas que apresenta uma limitação de gênero.

Avaliando outras dimensões da categoria, foi possível constatar considerável diversidade na faixa etária e no vestuário dos artistas. Entre os observados, havia desde um menino muito jovem, um malabarista de rua em Belo Horizonte, até homens de idade avançada, como o senhor que toca clarinete próximo à Livraria Cultura em São Paulo. Além disso, alguns profissionais vestiam fantasias e acessórios para a apresentação, apesar de a maioria vestir roupas casuais e não apresentar um figurino especifico para a ocasião.

A partir das observações, constatou-se que os artistas de rua enfrentam dificuldades constantes, tanto pessoais como artísticas. As dificuldades fisiológicas, como o tempo, calor ou frio, os longos períodos sem ingestão de água ou mesmo a ausência de banheiros públicos próximos, foram notadas em quase todas as observações. As dificuldades de execução nas apresentações também foram relatadas com frequência, principalmente com os instrumentos de trabalho, como a afinação de guitarras, o alto nível de ruído das vias, rouquidão dos cantores e até queimaduras com malabares em chamas. Também foi relatada, com frequência, a falta de segurança durante a performance dos artistas de rua, pois todos eles estavam expostos a ameaças voluntárias ou involuntárias, intrínsecas ao ambiente escolhido para a apresentação. A principal dificuldade observada foi a escassez de contribuições em dinheiro, pois o artista não tem controle sobre do fluxo ou montante de contribuições, mesmo quando a caixa para a colocação de dinheiro está bem à sua frente. No trecho abaixo foi descrito um momento de vulnerabilidade de um ator realizando performance de estátua viva.

Outras pessoas cutucavam o ombro dele e faziam caretas para provocar alguma risada ou movimento no artista. Na maior parte das ocasiões em que isso ocorreu, 0 artista manteve-se imóvel e sem responder aos estímulos externos, dirigindo 0 olhar para a caixa de moedas. Com a falta de reação, as pessoas que o provocavam desistiam e iam embora, algumas até deixaram alguma pequena contribuição para 0 artista. Além disso, existem pessoas que, ao ver a estátua viva, mudam o caminho pela calçada para distanciarem-se dela. Isso provavelmente decorre do medo de levar algum susto.

Pode-se afirmar que a atuação dos artistas está sujeita a vários riscos, devido à sua 
exposição ao ambiente. Uma inferência possível é que os artistas do gênero masculino são menos suscetíveis a violência física ou abusos, e essa é uma possível razão para a grande desigualdade de gênero observada. Nos relatos, as mulheres observadas demonstraram um comportamento mais tímido do que os homens. A única exceção foi a cantora Rocio, que se apresenta na avenida Paulista, e foi observada em duas ocasiões diferentes, porém em companhia de um saxofonista. A artista mostrou-se bastante experiente e comunicativa, procurando constantemente o contato com público, ao contrário das demais mulheres observadas, que se apresentavam de maneira coadjuvante no acompanhamento de artistas homens.

Em relação ao vestuário, o caso que mais chamou a atenção dos pesquisadores foi o de um menino malabarista em faróis da cidade de Belo Horizonte. Diferentemente de outros profissionais que trocavam de roupa e vestiam algum tipo de fantasia ou roupa estilizada, o malabarista mirim transformou-se, para a sua performance, em um "morador de rua", possivelmente um meio de aumentar a arrecadação dos motoristas que passavam pela rua. Ao acompanhá-lo até o fim da apresentação, foi possível notar que as roupas puídas eram a "fantasia", pois, ao finalizar as atividades, ele dirigiu-se a uma rua próxima para vestir roupas casuais e em bom estado que trazia em uma mochila.

\section{Arte}

0 artigo segundo da lei municipal n. 15.776, que legaliza o trabalho dos artistas nas ruas de São Paulo, define esse fenômeno de forma relativamente abrangente:
Art. $2^{\circ}$ : Compreendem-se como atividades culturais de artistas de rua, dentre outras, o teatro, a dança individual ou em grupo, a capoeira, a mímica, as artes plásticas, o malabarismo ou outra atividade circense, a música, o folclore, a literatura e a poesia declamada ou em exposição física das obras.

Embora os pesquisadores tenham realizado esforços para explorar todas as formas de arte disponíveis nas ruas, a maioria absoluta de observações foi de apresentações musicais. Foram observados tanto artistas atuando sozinhos quanto em conjunto. Essa forma de arte não é realizada apenas por cantores, mas também por instrumentistas como relatado na dupla de percussionistas na avenida Paulista. Uma possível explicação para o grande número de artistas de rua dedicados à música é a meIhor aceitação pelo público dessa forma de arte como atração gratuita.

Uma das grandes questões levantadas pela pesquisa é a importância do nível de profissionalização dos artistas. Essa questão foi suscitada pelo contraste entre a qualidade das apresentações dos artistas. Em várias observações, os artistas demonstravam bastante experiência e habilidade nas tarefas que desempenhavam. Muitos são relativamente famosos em redes sociais e reconhecidos pelo público, como por exemplo o cantor e guitarrista William Lee. No entanto, em alguns casos curiosos, os protagonistas desempenhavam performances teatrais que atraíam uma grande quantidade de pessoas e demoravam bastante até atingirem o ápice da exibição, ou seja, o momento em que o artista realmente realiza alguma tarefa que mereça a atenção do público. 
A atuação de um artista que realiza saltos acrobáticos na Praça da Sé, em São Paulo, é um bom exemplo desse tipo de apresentação. 0 protagonista atuava inicialmente sozinho, porém, ao longo de sua apresentação, uma muIher passou a ajudá-lo, e tinha uma aparência pitoresca. Ele se apresentava com roupas aparentemente sujas, sem camisa nem sapatos e com o cabelo despenteado. Faltavam-lhe diversos dentes. À sua frente, havia um arco de metal apoiado na vertical sobre um pedestal com facas de cozinha apontadas para o centro. Ele chamava as pessoas ao seu redor anunciando 0 tempo todo que, a qualquer momento, ele iria pular e atravessar o obstáculo. Entretanto, 0 artista demorava muito mais tempo para entreter o público e atiçá-lo pela curiosidade sobre qual seria o final da sua apresentação. Conforme o diário de campo, pode-se perceber a demora em concluir uma apresentação aparentemente simples, mas o quanto isto atrai e causa euforia no público espectador:

Os gritos dos observadores começam a aumentar, mais pessoas gritam para incentivar o artista, alguns gritam para desafiá-lo, outros gritam para que ele complete logo o espetáculo por já estarem cansados de esperar. 0 homem pede mais espaço, pede para os observadores darem um passo atrás. Ele pega novamente uma faca e introduz no nariz, fazendo caretas e movimentos amplos e espalhafatosos. Tira a faca do nariz e se posiciona como se fosse saltar. 0 homem já está a $10 \mathrm{mi}-$ nutos posicionado como se fosse saltar, e o público demonstra impaciência. Alguns vão embora, e outros que estão passando se aproximam. Nesse momento, atinge-se o número máximo de espectadores desde 0 início do relato, aproximadamente 25 pessoas cercam 0 artista. A mulher que segura o círculo de facas aumenta os gritos de desafio, e o homem finalmente pula pelo círculo de facas, aterrissando com uma cambalhota do outro lado. A conclusão da performance traz euforia a muitos que o observam, muitos gritos e aplausos se seguem à apresentação. 0 homem abre os braços e agradece ao público. Alguns se aproximam para abraçá-lo e tocá-lo. Ele tira algumas facas do círculo de facas e introduz novamente no nariz. Nesse momento, a mulher que o acompanha pega uma sacolinha de pano e passa no meio dos observadores pedindo dinheiro, e a grande maioria das pessoas deposita alguma coisa para o homem, moedas e notas de pequeno valor.

Outro exemplo desse estilo de apresentação é o do grupo de mágicos no centro de São Paulo. Nesse caso, três homens se revezavam para atrair o máximo possível de pessoas ao redor do palco improvisado, executando truques de ilusionismo. Somente um deles parecia realmente ser experiente com as performances, cuja apresentação era o clímax do grupo e responsável pela grande concentração do público. A apresentação do grupo era cíclica; o artista habilidoso se revezava com os outros dois menos experientes para atrair a massa durante a "troca" de plateia, já que, passado algum tempo, o grupo repetiria os mesmos truques de mágica. Assim como o artista que pulava as facas, os mágicos demoravam bastante tempo nas suas performances, aproveitando ao máximo a curiosidade do público para o desfecho da apresentação.

Assim, ainda que esses artistas "sensacionalistas" apresentem uma profissionalização adaptada, principalmente se comparada aos artistas mais experientes, eles conseguiam atrair uma enorme quantidade de espectadores. 
Muitas vezes, os artistas mais populares conseguiam públicos significativamente maiores que os músicos de alto nível de profissionalização e grande qualidade de execução técnica. Dessa maneira, pode-se inferir que, no fenômeno dos artistas de rua, o nível de profissionalização não interfere necessariamente no aumento da audiência e, consequentemente, na maior arrecadação financeira. Essas evidências também trazem dúvidas sobre a definição do que é ser um artista profissional. Se, por definição, a profissionalização implica a habilidade, na experiência e na arte como meio de subsistência do indivíduo, esses artistas podem ser considerados profissionais, embora a sua arte não seja compreendida dessa forma pelo público. Essas performances não somente são consideradas amadoras, como os artistas são popularmente definidos como "loucos", conforme os comentários de algumas pessoas do público anotados nos diários de campo.

A última consideração sobre a categoria "Arte" envolve a tendência de os artistas de rua dirigir sua atenção para o público, interagindo constantemente com as pessoas no intuito de ter maior audiência. Em uma leitura preliminar, pareceu óbvio encontrar a causalidade para esses aspectos: interagir com o máximo de carisma para arrecadar o máximo possível de dinheiro. Um exemplo dessa atuação foi o imitador de Elvis Presley que se apresenta na avenida Paulista. Em um certo momento da apresentação, ele modifica o repertório exclusivo de músicas do Rei do Rock para cantar músicas mais populares, como a música Camaro Amarelo da dupla Munhoz e Mariano, para chamar a atenção das pessoas que passavam no local. Conforme descrito no relatório:
Ao voltar às atividades, 0 imitador de Elvis deixou de lado as músicas clássicas do Rei do Rock e passou a tocar algumas músicas populares, que tocam com frequência nas rádios e que têm grande apelo popular. As músicas sertanejas passaram a dominar o repertório do artista. Juntamente com as letras, 0 artista incorporava as danças típicas. Aparentemente, com essas músicas populares as pessoas ficaram mais interessadas na apresentação ou mesmo dedicavam maior atenção ao artista. Percebe-se que algumas pessoas até dançavam as músicas cantadas por ele, alguns de maneira mais tímida e outros de maneira mais ousada, geralmente garotas jovens em grupo.

Apesar de a maioria dos artistas observados utilizar essa estratégia de chamar a atenção, foram relatados alguns que não realizavam nenhum esforço para se comunicar com o público. Eles tinham orientação exclusiva para a própria performance e execução e, mesmo assim, muitos conseguiam arrecadar tanto dinheiro quanto os artistas de comportamento proativo. Em resumo, esse fenômeno evidencia uma das observações mais relevantes deste trabalho: a comunicação verbal direta com o público utilizada por vários artistas tem uma contrapartida negativa. 0 ato de pedir uma contribuição em dinheiro reforça uma percepção comum nos relatos de que esses trabalhadores são pedintes e não artistas de fato.

\section{Ambiente}

Todos os ambientes das apresentações observadas eram locais bastante movimentados, sobretudo as regiões centrais das cidades. Muitas das vias, como por exemplo a avenida Paulista, 
eram bastante barulhentas, atrapalhando principalmente os artistas musicais. Muitas vezes, com a passagem de carros e ônibus pela via, era impossível ouvir o som produzido pelos artistas, mesmo aqueles que utilizavam amplificadores de som como infraestrutura principal. Os ruídos atrapalhavam ainda mais os artistas que utilizavam o playback de melodia, normalmente a parte instrumental de uma música conhecida tocada em uma caixa de som para o artista cantar ao vivo por cima.

Muitos dos artistas improvisavam palcos para suas apresentações, utilizando geralmente um pano grande no chão ou um tapete demarcando o espaço da performance. Naturalmente, alguns tipos de arte demandavam uma preparação de ambiente maior do que outras. Por exemplo, a localização de uma bateria e de amplificadores de uma banda de quatro integrantes demandava um preparo muito maior do que o espaço demarcado para a atuação de um artista que se apresenta como estátua viva ou para a exposição de quadros de um pintor. Ainda assim foi possível notar uma preocupação grande de vários artistas em detalhar 0 ambiente escolhido para a apresentação. Quadros, placas, altares, dentre outros objetos, compunham os espaços observados, embora a maioria não dedique muitos esforços cenográficos.

Os pesquisadores relataram que o horário das apresentações interferia de algum modo na atenção do público para com o artista. Durante o dia, muitas pessoas que passavam pelos locais escolhidos pelos artistas estavam em horário de trabalho ou de almoço. Presume-se que, por estarem ocupadas ou preocupadas com outras questões, não prestavam muita atenção nos artistas de rua, demonstrando indiferença à presença deles. Durante a noite, no entanto, a disponibilidade do público para apreciar algum artista era muito mais natural. É possível supor que nesse horário a maior parte do público já havia cumprido seus compromissos de trabalho e, portanto, estaria mais relaxada e propensa a apreciar a performance dos artistas. Sendo assim, o horário de atuação dos artistas de rua influencia, de alguma inequívoca, a atenção da audiência.

Também foram identificadas algumas estratégias dos artistas de rua para atrair mais público. Um caso de destaque foi o dos mágicos do Centro de São Paulo. Por se tratar de truques de "ilusionismo", essa arte dependia da proximidade do público ao redor dos artistas. Assim, cada vez que os artistas precisavam aproximar a plateia para si, eles demarcavam com um jato de água disparado por uma garrafa plástica o local onde as pessoas deveriam se localizar. Essa prática era acompanhada de gritos de incentivo dos artistas, pedindo a aproximação de todos para melhor observar os truques, conforme descrito no relatório de campo:

Os mágicos utilizam jatos de uma garrafa com água para demarcar o espaço que as pessoas devem ocupar para formar o círculo de espectadores. É um meio que eles usam para aproximar ou distanciar o público, de acordo com a quantidade de pessoas que está observando em cada momento.

Esse exemplo mostra a importância da escolha do ambiente para uma boa execução do artista. Ainda assim, a questão mais importante evidenciada pelas observações sobre a categoria de análise "Ambiente" envolve a diferença das performances em regiões mais populares e em regiões mais nobres das cidades observadas. Um exemplo clássico dessa 
constatação foram as comparações entre as apresentações da avenida Paulista e do Centro histórico de São Paulo e os respectivos perfis do público nesses locais, independentemente do tipo de arte apresentada. Nas regiões mais populares, percebe-se um envolvimento maior do público com o artista. 0 público aparenta ser de classe de menor poder aquisitivo e tem maior propensão a contribuir financeiramente com os artistas. É possível supor que existe, nesse contexto, uma relação de identidade dessas pessoas com os artistas. Na observação do cantor William Lee, a cada vez que o intérprete discursava sobre a história de sua vida e as dificuldades que enfrentou, o público, já atraído pela sua habilidade artística, mostrava-se mais interessado e sensibilizado com 0 artista.

Essa dedicação, no entanto, não era percebida em regiões mais nobres ou empresariais, como a da avenida Paulista. Embora também houvesse músicos que discursassem para os espectadores entre uma música e outra, poucas pessoas pareciam prestar atenção no que eles diziam. Além disso, nas regiões mais ricas, era muito maior o contraste entre a aparência do público e a do artista. Esta é, provavelmente, uma das causas do nível maior de profissionalização dos artistas da avenida Paulista, como a preparação de vestuário e de acessórios. Isso traz indícios de que os artistas têm maior cuidado com os detalhes cênicos nos locais mais ricos da cidade.

\section{Público}

0 aspecto mais intrigante das observações com referência à categoria "Público" é a diferença de comportamento nas diversas faixas etárias. Ao mesmo tempo que o público mais jovem se mostra mais receptivo às performances dos artistas, as pessoas idosas rejeitam as atividades dos profissionais, por vezes de maneira ostensiva.

Sobre a atitude dos mais jovens, quase todos os relatos abordam a grande admiração e o entusiasmo das crianças com os artistas, o que pode ser entendido como uma demonstração da curiosidade típica da idade. Como foram frequentes o relato da interação das crianças com os artistas e a atitude dos pais que encorajavam o divertimento das crianças, os pesquisadores concluíram que se tratava de um fato importante. Esse fenômeno ocorreu nos diferentes tipos de arte, inclusive nas estátuas vivas, apesar de boa parte das crianças se assustar ao primeiro contato com esses intérpretes. Nas apresentações musicais, notou-se com maior intensidade essa relação, com crianças frequentemente dançando bem na frente dos artistas.

0 público jovem não se resumiu apenas a crianças, já que foram notados muitos adolescentes e jovens adultos, na faixa dos vinte anos de idade, nas observações. Muitos deles passavam pelos locais devido à proximidade com shoppings e outros estabelecimentos de entretenimentos próximos dos locais de observação. Apesar de muitos dos jovens não contribuírem financeiramente, a maioria absoluta desse público tinha apreço e parecia reconhecer o trabalho dos artistas.

Em oposição, os mais idosos pareceram ter uma aversão às apresentações dos artistas de rua, já que muitos não foram apenas indiferentes às performances, mas demonstraram estar incomodados com elas. Isto era muito comum, por exemplo, em apresentações próximas a pontos de ônibus ou cafés, localizações 
onde as pessoas tinham dificuldade de se afastar do som dos artistas e eram obrigadas a ouvir a apresentação contra a própria vontade.

Para identificar a opinião do público com relação aos artistas, era muito mais fácil para os pesquisadores avaliar as pessoas e os transeuntes que estavam acompanhados, pois eles expressavam, aos seus pares, suas opiniões a respeito da arte, verbal e gestualmente. Esses casos foram fundamentais para a identificação de interações muito amistosas e muito negativas do público em relação aos artistas. As reações das pessoas mais idosas, em sua maioria de reprovação, foram percebidas dessa maneira, ao afirmarem umas para as outras sobre a hipótese de que os artistas tinham demasiado tempo ocioso ou mesmo que eles deveriam procurar algum outro tipo de trabaIho ou ocupação mais útil. Conforme descrito no Relatório 18:

No meio da observação, entrei na drogaria bem na frente da apresentação dos artistas para comprar um medicamento. A atendente me disse boa tarde e me perguntou o que eu desejava. Mostrei a receita, e ela pediu licença para ir buscar o medicamento. Enquanto ela anotava os códigos dos remédios que eu ia comprar, ela comentou com a farmacêutica do lugar:

- Aí, trabalhar com esse barulho tá difícil hein... Esses caras não têm o que fazer não?

A farmacêutica parecendo concordar com a atendente, somente comenta:

- "Batucada, né?"

$\mathrm{Na}$ fila para o pagamento, percebo que as pessoas que esperam junto a mim também ficam observando os artistas, mas não mostram nenhuma reação.
Além do público mais jovem, as opiniões e os gestos mais amistosos foram observados nos horários noturnos, conforme já mencionado no tema ambiente. Na apresentação de uma dupla musical na avenida Paulista por volta das 19h, os artistas pareciam apresentar-se em um show aberto, algo semelhante a um happy hour, já que grande parte dos espectadores estava conversando em rodas de amigos e como se estivesse em um bar. Eram também nessas ocasiões que os artistas mais aproveitavam para divulgar o seu trabalho, geralmente vendendo produtos da sua arte. Esta é uma prática recentemente regularizada pela lei dos artistas de rua, conforme o artigo terceiro:

Art. $3^{\circ}$ Durante a atividade ou evento, fica permitida a comercialização de bens culturais duráveis como CDs, DVDs, livros, quadros e peças artesanais, desde que sejam de autoria do artista ou do grupo de artistas de rua em apresentação e que sejam observadas as normas que regem a matéria. ${ }^{4}$

A venda desses produtos era, na maioria dos casos, a maior fonte de renda nas apresentações dos artistas de rua, não somente com produtos físicos como CD's e pinturas, mas também na divulgação de cartões para eventos. Constatou-se que, embora muitos artistas pedissem contribuições financeiras ao público durante a sua performance com uma caixa ou um chapéu destinado para a arrecadação, grande parte da renda deles era originada da venda de produtos. 0 fenômeno dos artistas na rua mostrou-se como uma "amostra grátis" ou propaganda de seus trabalhos, que poderiam ser contratados futuramente. 
Um último ponto observado pelos pesquisadores no que se refere à categoria "Público" tem relação com aparente classe econômica e social. É importante relatar a existência de uma relação de identidade entre o público que aparenta ter menor renda e o artista que expõe as histórias pessoais de vida e de dificuldades. É bastante relevante o fato de que é o público com perfil mais simples que mais contribui financeiramente com o fenômeno "artistas de rua", isto é, dá contribuições pelas performances ao vivo desses profissionais. Foi observada, inclusive, a participação ativa de moradores de rua, que pareciam desfrutar das apresentações, por se tratar de uns dos poucos entretenimentos disponíveis gratuitamente na cidade. Os artistas de rua, por sua vez, pareciam bastante familiares com esse tipo de público, até mesmo mantendo conversas com eles.

Em contrapartida, além dos mais idosos, o público que teve mais atitudes de reprovação foi 0 as pessoas que aparentava ter maiores níveis de renda, considerando, dentre outros, seu vestuário. Além de não contribuírem financeiramente, muitos mostravam desaprovar, verbal ou gestualmente, a atitude de se apresentar nas ruas, gratuitamente e em horário comercial. Dessa maneira, além de possuir uma relação direta com o local de performance do artista, a renda do público também possui uma relação com o tipo de arte apresentada pelos artistas na rua.

\section{Interação}

A categoria "Interação" abrange, de certa forma, todos as categorias anteriores, pois questões envolvendo a "Arte" e /ou o "Ambiente" também estão presentes.

Ao final das observações e das análises, constatou-se que a maioria do público tem uma reação indiferente quanto às performances dos artistas de rua. É possível supor que isso se deva, em parte, ao fato de os artistas de rua se apresentarem regularmente nos mesmos locais, ambientes em que o público também frequenta diariamente. A partir dessa constatação, as observações dos pesquisadores concentraram-se nas pessoas que tinham alguma reação observável, fosse ela positiva ou negativa, sobre as apresentações dos artistas.

A interação entre artista e público ocorria de diversas maneiras, algumas mais explícitas, como no caso da dupla de cantores da avenida Paulista, que saía de seus locais de performance e ia falar pessoalmente com pessoas que a assistiam, ou na movimentação e no oferecimento de flores de uma estátua viva ao receber alguma contribuição em dinheiro. Entretanto, ao final das análises, foram relatadas várias ocasiões em que o comportamento ativo por parte do artista não resultou em maior arrecadação de dinheiro. Foi possível observar artistas bastante introvertidos, inclusive músicos, que recebiam muitas contribuições financeiras do público devido à admiração pela performance. As reações tímidas dos artistas eram nítidas até nos agradecimentos pelas "gorjetas" recebidas. Em alguns momentos, a falta de uma expressão mais clara era compreendida como ingratidão por parte do público que contribuía. A passagem a seguir exemplifica essas reações:

0 artista retribuía algumas vezes com um sonoro "Obrigado!", ou com um gesto positivo com a cabeça. Entretanto, para 
alguns espectadores, o artista não esboçava nenhum gesto ou palavra de agradecimento. Muitas vezes, as gorjetas eram depositadas com bastante frequência e rapidez, e o artista nem tinha tempo de olhar para todos que contribuíam. Isso não aparentava ser desconsideração, mas uma característica da performance, pois em alguns momentos tocava de olhos fechados ou concentrado na execução da música. Ainda assim, era possível perceber um leve sinal de desaprovação ou de desapontamento daqueles que não receberam um agradecimento claro por parte do músico.

Ainda sobre a contribuição financeira, foi possível perceber um certo ritual das pessoas ao assistirem à apresentação de um artista de rua. A maioria dos contribuintes parava de caminhar ao notar a performance do artista, prestava atenção na arte e somente deixava a gorjeta na hora de ir embora. Foram raríssimas as pessoas que deram dinheiro logo no início de sua observação ou que deixaram o dinheiro no local destinado sem parar para assistir à apresentação.

Outro ponto importante na interação entre artista e público foi o uso de celulares smartphones por parte dos espectadores para gravar, por meio de fotos ou vídeos, as performances dos artistas. Os artistas reagiram de maneira bastante natural a esse comportamento. Muitos dos artistas faziam poses para o público nessas circunstâncias. Alguns deles chegaram a manifestar diretamente a receptividade a esse tipo de interação, informando as hashtags para encontrá-los nas redes sociais: Twitter, Facebook e Instagram, para estimular a divulgação de fotos e vídeos realizados durante as apresentações. Dessa maneira, a interação virtual demonstrou ser uma estratégia bastante utilizada para a divulgação dos trabalhos dos artistas de rua.

Em relação à percepção do público sobre as dificuldades enfrentadas pelos artistas de rua, as pessoas aparentemente mais humildes eram as que mais contribuíam financeiramente pela performance a que assistiam. Entretanto, foi possível identificar outros perfis de público que demonstraram maior propensão a dar gorjetas para os artistas. Primeiramente, os turistas, sobretudo em grande concentração na avenida Paulista, surpreendiam-se facilmente com os artistas de rua, talvez pela novidade ou pelo caráter exótico de alguns deles. A maioria parava para prestar atenção nas apresentações e contribuía com dinheiro. Outro perfil muito comum de interação amistosa e com dinheiro foi de outras pessoas que aparentavam também praticarem alguma forma de arte. Essa suposição foi baseada nas roupas, nas longas conversas que tinham com os artistas ou no fato de carregarem consigo um instrumento musical. Foi o que aconteceu com a dupla de percussionistas que tocava na avenida Paulista e foi interrompida por um saxofonista que, ao passar diante da apresentação, abriu a mochila e começou a tocar músicas juntos. Por fim, o último perfil de pessoas que mais contribuíam era 0 das que aparentavam estar fora do horário de trabalho ou em horário de intervalo. Os fumantes eram um público relativamente frequente, pois são obrigados a sair dos prédios em que trabalham e ficar na calçada para fumar. 


\section{Conclusões e considerações finais}

Conforme a análise dos códigos extraídos das observações, percebe-se, em geral, a presença das seguintes relações dos artistas de rua:

- Ambiente versus Tipo de profissionalização do artista

- Ambiente (horário) versus Interação (como arrecadação de dinheiro)

- Reação do público versus Pessoas em grupos e Faixa etária

- Infraestrutura versus Profissionalização

- Dificuldades de execução versus Profissionalização

- Tipos de arte versus Perfil da audiência

- Perfil de renda do público versus Forma como os artistas arrecadam dinheiro (ou perfil da audiência)

0 fato de a maioria das observações ter sido feita com músicos demonstra o quanto 0 termo "artistas de rua" ainda é considerado sinônimo de "músico que busca a fama" ou de indivíduos que se apresentam nas ruas para complementar a renda. Como muitos artistas ainda utilizam a interação ativa como estratégia para arrecadar dinheiro, muitos são vistos pela maioria da população como pedintes ou, no mínimo, como artistas pouco profissionais. Mesmo aqueles que adquiriram algum tipo de notoriedade, sobretudo nas redes sociais, não são vistos pelo público como verdadeiros profissionais, mas, no máximo, como pessoas construindo uma carreira artística. Pode-se dizer, portanto, que os artistas de rua, intencionalmente ou não, possuem pouca visão de negócios, já que não aproveitam o potencial de visibilidade que possuem com o público para desenvolver novas estratégias para atrair mais audiência e ganhar mais dinheiro.

0 ambiente de apresentação dos artistas de rua sugere um choque de classes econômicas e sociais, na medida em que pessoas que aparentam ser de classes de menor poder aquisitivo são mais atenciosas com as performances e, inclusive, dão mais dinheiro para os artistas. Essa questão socioeconômica parece ser muito influente na vida dos artistas de rua, pois relaciona-se também com o público de maior poder aquisitivo. Aqueles que são aparentemente mais "ricos", vestidos com trajes sociais ou com roupas de marcas conhecidas, raramente oferecem atenção aos artistas. Algumas hipóteses para explicar esse comportamento são a pressa em locomover-se nas ruas da cidade, 0 medo de ficar parado na calçada e ser furtado, a dificuldade em apreciar a performance por causa do ruído ou mesmo a não percepção da apresentação dos artistas como um trabalho e sim como um pedido de esmola.

A questão de classe também atinge os próprios artistas, pois existe uma certa elitização daqueles que já possuem alguma fama ou têm o trabalho divulgado em redes sociais e na mídia televisiva. Os artistas mais famosos apresentam um comportamento diferente daqueles que são completamente desconhecidos. Alguns exibem, durante a apresentação nas ruas, reportagens, recortes de jornal e entrevistas impressas das quais participaram. Além disso, o fato de terem alguma visibilidade prévia parece influenciar a escolha do local de sua performance.

Percebem-se, assim, duas grandes características que interferem diretamente na apresentação do artista e no perfil da audiência: o local de atuação (se é movimentado ou não 
e principalmente se é popular ou não) e uma adaptação da arte para o gosto popular (como o exemplo citado do "Elvis da Paulista" cantando músicas sertanejas). Alguns artistas utilizam estratégias para chamarem mais atenção, como o suspense, a construção de uma grande expectativa para o ápice da apresentação ou mesmo a conversa direta com o público. De modo geral, essas ações ativas parecem ter como objetivo mais prender a atenção do público do que obter uma contribuição financeira.

0 trabalho dos artistas de rua se apresenta como uma manifestação democrática, pois abrange constantemente diversos perfis de pessoas, em situações cotidianas variadas e pode ocorrer em diferentes horários e locais da cidade. Para o artista, essa diversidade é importante para enriquecer o trabalho, quase intrinsicamente permeado por dificuldades. Conclui-se que a grande preocupação desses artistas não é somente trabalhar para obter uma renda de subsistência, mas utilizar as ruas como experiência para apresentações e, consequentemente, para oferecer algum tipo de entretenimento para o público, ainda que este não o reconheça ou não aprecie o seu trabalho.

\section{Bruno Buscariolli}

Fundação Getúlio Vargas, Escola de Administração de Empresas de São Paulo, Departamento de Administração de Empresas. São Paulo, SP/Brasil.

bruno.buscariolli@gmail.com

\section{Adele de Toledo Carneiro}

Fundação Getúlio Vargas, Escola de Administração de Empresas de São Paulo, Departamento de Administração de Empresas. São Paulo, SP/Brasil.

carneiro.at@gmail.com

\section{Eliane Santos}

Fundação Getúlio Vargas, Escola de Administração de Empresas de São Paulo, Departamento de Administração de Empresas. São Paulo, SP/Brasil. efseliane@yahoo.com.br

\section{Notas}

(1) Disponível em: http://www3.prefeitura.sp.gov.br/cadlem/secretarias/negocios_juridicos/ cadlem/integra.asp?alt=30052013L+157760000. Acesso em: 31 de jul 2015.

(2) Brasil de Fato, 11 de março de 2014.

(3) Disponível em: www.artistasnarua.gov.br. Acesso em: 31 jul2015.

(4) Disponível em: http://www3.prefeitura.sp.gov.br/cadlem/secretarias/negocios_juridicos/ cadlem/integra.asp?alt=30052013L+157760000. Acesso em: 31 jul 2015. 


\section{Referências}

ARTISTAS NA RUA (2015). Disponível em: www.artistasnarua.com.br. Acesso em: 13 set 2016.

BRASIL DE FATO (11/3/2014). Disponível em: https://antigo.brasildefato.com.br/node/28117/. Acesso em: 13 set 2016 .

CZARNIAWSKA, B. (2007). Shadowing and other techniques for doing fieldwork in modern societies. Liber, Copenhagen Business School Press.

FLORES-PEREIRA, M. T. e CAVEDON, N. R. (2009). Os bastidores de um estudo etnográfico: trilhando os caminhos teórico-empíricos para desvendar as culturas organizacionais de uma livraria de shopping center. Cadernos Ebape. BR. Rio de Janeiro, v. 7, n. 1.

GODOI, C.; BANDEIRA-DE-MELLO, R. e SILVA, A. (2006). Pesquisa Qualitativa em Organizações: Paradigmas, Estratégias e Métodos. São Paulo, Saraiva.

HAMMERSLEY, M. e ATKINSON, P. (1995). Ethnography: principles in practice. Nova York, Routledge.

MALINOWSKI, B. K. (1976). Os pensadores: argonautas do Pacífico Ocidental: um relato do empreendimento e da aventura dos nativos nos Arquipélagos da Nova Guiné Melanésia. São Paulo, Abril Cultural.

SANDAY, P. R. (1979). The ethnographic paradigm(s). Administrative Science Quarterly, v. 24, pp. 527-538.

SCHWANDT, T. A. (2006). "Três posturas epistemológicas para a investigação qualitativa: interpretativismo, hermenêutica e construcionismo social”. In: DENZIN, N. K. e LINCOLN, Y. S. O planejamento da pesquisa qualitativa: teorias e abordagens. Porto Alegre, Bookman.

VAN MAANEN, J. (1979). The fact of fiction in organizational ethnography. Administrative Science Quarterly, v. 24, pp. 539-550.

(2006). Ethnography then and now. Qualitative Research in Organizations and Management, v. 1 , n. 1 , pp. $13-21$.

Texto recebido em 14/jan/2016 Texto aprovado em 31/mar/2016 